\title{
Can long-term care facilities remain a coronavirus disease 2019 (COVID-19)-free bubble? An outbreak report
}

\author{
Tomás Robalo Nunes $\mathrm{MD}^{1,2, \mathrm{a}}$ (1), Dan Lebowitz $\mathrm{MD}^{1, \mathrm{a}}$, Marlène Fraccaro $\mathrm{RN}^{1}$, Monique Perez $\mathrm{RN}^{1}$, Laure Vieux $\mathrm{MD}^{3}$, \\ Mohamed Abbas MD, MS ${ }^{1,4}$, Christophe Graf MD ${ }^{5}$ and Stephan Harbarth MD, MS ${ }^{1}$ \\ ${ }^{1}$ Infection Control Programme and WHO Collaborating Centre on Patient Safety, Geneva University Hospitals and Faculty Medicine, Geneva, Switzerland, \\ ${ }^{2}$ Infectious Diseases Service, Hospital Garcia de Orta, EPE, Almada, Portugal, ${ }^{3}$ Occupational Medicine Service, Geneva University Hospitals, Geneva, Switzerland, \\ ${ }^{4}$ Health Protection Research Unit, Imperial College London, London, United Kingdom and ${ }^{5}$ Internal Medicine and Rehabilitation Service, Rehabilitation and \\ Geriatrics Department, Geneva University Hospitals, Geneva, Switzerland
}

To the Editor-Coronavirus disease 2019 (COVID-19) has caused numerous outbreaks in healthcare settings ${ }^{1,2}$ and long-term care facilities (LTCFs), ${ }^{3-5}$ being associated with high morbidity and mortality. ${ }^{6}$ Recently, a group of epidemiologists and public health experts issued the Great Barrington Declaration arguing in favor of the concept of "focused protection." It advocates targeted confinement of people at risk, including residents of LTCFs, allowing people without risk factors for severe COVID-19 to live normally.

To challenge this theoretical concept of creating COVID-free bubbles in LTCFs, completely separated from the outside pandemic world, we report an outbreak of healthcare-associated COVID-19 in a Swiss tertiary-care hospital with subsequent spillover to affiliated LTCFs that occurred between September 18 and October 12, 2020. Specifically, we describe how a social event among healthcare workers (HCWs) and presymptomatic transmission likely led to severe acute respiratory syndrome coronavirus 2 (SARS-CoV-2) cross infections in "COVID-free" wards with vulnerable patients.

On September 21, 2020, a 79-year-old woman presented with fever and respiratory symptoms 7 days after admission to a surgery ward and tested positive by PCR for SARS-CoV-2. The epidemiologic investigation of this possible hospital-acquired COVID-19 revealed that $2 \mathrm{HCWs}$ who were in direct contact with the patient had developed respiratory symptoms since September 18; their SARS-CoV-2 RT-PCR assays were positive on September 22. Contact tracing showed that they participated with 20 colleagues in a social event on the day of onset of symptoms, mostly from the same surgical ward, suggesting a possible cluster of healthcare-associated SARS-CoV-2 infections.

These observations led to an investigation with SARS-CoV-2 screening of all patients and HCWs of the concerned ward, regardless of symptoms. The surgical ward was closed to new admissions and patient transfers were cancelled. All patients who had stayed in the surgical ward since the onset of the outbreak were defined as potential cases, were screened for SARS-CoV-2, and were kept on pre-emptive droplet precautions. Patients with positive SARSCoV-2 PCR or COVID-19-compatible symptoms were placed under contact and droplet precautions. All suspected patients were retested on day 5 after a negative initial testing, and on day 10 if the second test was also negative.

Author for correspondence: Dan Lebowitz, E-mail: dan.lebowitz@hcuge.ch

aAuthors of equal contribution.

Cite this article: Robalo Nunes T, et al. (2022). Can long-term care facilities remain a coronavirus disease 2019 (COVID-19)-free bubble? An outbreak report. Infection Control \& Hospital Epidemiology, 43: 410-411, https://doi.org/10.1017/ice.2020.1432
HCWs were defined as potential cases if they worked in the same surgical ward during the outbreak period, participated in the aforementioned social event, or had a close contact ${ }^{8}$ with other HCWs with confirmed SARS-CoV-2 infection during the outbreak period. HCWs were strongly encouraged to follow the same strategy as patients. SARS-CoV-2-positive HCWs were placed on sick leave.

In total, 18 patients and 32 HCWs underwent PCR testing for SARS-CoV-2 in the surgical ward: 7 patients were positive (attack rate, 39\%); 4 developed symptoms compatible with COVID-19; and 3 remained asymptomatic. Furthermore, $17 \mathrm{HCW}$ s tested positive for SARS-CoV-2 (attack rate, 53\%), of whom 11 had participated in the social event outside the hospital.

On September 24, 3 days after being transferred from this surgical ward to an external, hospital-affiliated LTCF, an elderly female patient developed symptoms and tested positive. Following this finding, we applied the same screening strategy to all patients and HCWs in the LTCF ward. In total, 4 patients (attack rate, 21\%) and $4 \mathrm{HCWs}$ tested positive for SARS-CoV-2. Unfortunately, 1 confirmed patient from the LTCF had already been transferred to another ward in the same LTCF prior to the development of symptoms. In this second ward, 7 additional patients (attack rate, 29\%) and $4 \mathrm{HCW}$ s tested positive for SARS-CoV-2. There were 2 patient deaths in the 30 days after diagnosis of SARS-CoV-2 infection. Figure 1 summarizes the transmission pathways and the 3 clusters.

Although the first documented SARS-CoV-2 case in the surgical ward was a patient, our epidemiologic investigation strongly suggests that a super-spreading event among HCWs was the trigger event of this large nosocomial outbreak. Many HCWs participated in this social event with other HCWs from the same ward, without social distancing or masking. We hypothesize that SARS-CoV-2 was thereafter introduced into the acute-care setting by HCWs who contaminated colleagues through close contacts as well as patients during care activities and that these HCWs acted with insufficient adherence to standard infection control practices including hand hygiene.

Conversely, the probable means of introduction of SARS-CoV-2 infection in the LTCF was the transfer of an asymptomatic patient from the hospital to the LTCF during incubation. Silent transmission of SARS-CoV-2 by patients has been described in the literature, ${ }^{4,5}$ and it played a key role for the introduction of SARS-CoV-2 in 2 wards of our LTCF.

The main study limitation is the lack of genomic sequencing data, but the extent of spread during the outbreak was disproportionate compared to that in the Geneva community with still low

(c) The Author(s), 2021. Published by Cambridge University Press on behalf of The Society for Healthcare Epidemiology of America. This is an Open Access article, distributed under the terms of the Creative Commons Attribution licence (http://creativecommons.org/licenses/by/4.0/), which permits unrestricted re-use, distribution, and reproduction in any medium, provided the original work is properly cited. 


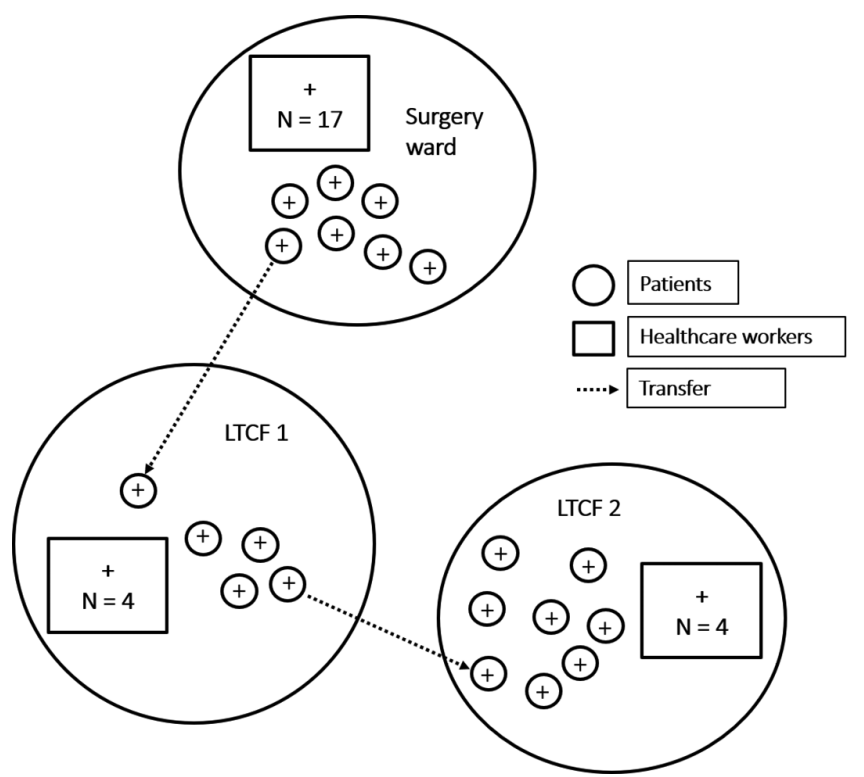

Fig. 1. Schematic representation of transmission chains between the surgical ward and 2 wards in a hospital-affiliated long-term care facility (LTCF). Patients are represented as circles. Healthcare workers are represented as squares.

incidence, confirming an expanded cluster of infections in the involved wards.

This outbreak report highlights the ease of transmission between various settings, including the community, the acute-care setting, and affiliated LTCFs, involving asymptomatic patients. It seems indeed impossible to control the social life of HCWs, just like that of any other individual. Furthermore, HCWs are at the interface between hospitals and the community, always at risk to silently introduce SARS-CoV-2 in the workplace. ${ }^{9,10}$ Daily screening of HCWs seems an unrealistic concept on a large scale. Therefore, healthcare facilities can hardly remain a SARS-CoV-2-free bubble, especially as the prevalence in the community rises.
Acknowledgments. We thank all members of the infection control program and all HCWs involved in the analysis of this outbreak.

Financial support. No financial support was provided relevant to this article.

Conflicts of interest. All authors report no conflicts of interest relevant to this article.

\section{References}

1. Gao S, Yuan Y, Xiong Y, et al. Two outbreaks of SARS-CoV-2 in department of surgery in a Wuhan hospital. Infect Prev Pract 2020;2:100065.

2. Kim SW, Jo SJ, Lee $\mathrm{H}$, et al. Containment of a healthcare-associated COVID-19 outbreak in a university hospital in Seoul, Korea: a single-center experience. PLoS One 2020;15:e0237692.

3. Dora A V., Winnett A, Jatt LP, et al. Universal and serial laboratory testing for SARS-CoV-2 at a long-term care skilled nursing facility for veteransLos Angeles, California, 2020. Morb Mortal Wkly Rep 2020;69:651-655.

4. Kimball A, Hatfield KM, Arons M, et al. Asymptomatic and presymptomatic SARS-CoV-2 infections in residents of a long-term care skilled nursing facility-King County, Washington, March 2020. Morb Mortal Wkly Rep 2020;69:377-381.

5. Arons MM, Hatfield KM, Reddy SC, et al. Presymptomatic SARS-CoV-2 infections and transmission in a skilled nursing facility. $N$ Engl J Med 2020;382:2081-2090.

6. Graham NSN, Junghans C, Downes R, et al. SARS-CoV-2 infection, clinical features and outcome of COVID-19 in United Kingdom nursing homes. J Infect 2020;81:411-419.

7. Great Barrington Experiment. Great Barrington Declaratin website. https:// gbdeclaration.org/. Published October 4, 2020. Accessed January 5, 2021.

8. Isolation and quarantine. Swiss Federal Office of Public Health. https:// www.bag.admin.ch/bag/en/home/krankheiten/ausbrueche-epidemienpandemien/aktuelle-ausbrueche-epidemien/novel-cov/isolationund-quarantaene.html. Published 2020. Accessed January 5, 2021.

9. Sikkema RS, Pas SD, Nieuwenhuijse DF, et al. COVID-19 in healthcare workers in three hospitals in the south of the Netherlands: a cross-sectional study. Lancet Infect Dis 2020;20:1273-1280.

10. Asad H, Johnston C, Blyth I, et al. Healthsare workers and patients as trojan horses: a COVID19 ward outbreak. Infect Prev Pract 2020;2:100073.

\title{
Medical facemasks are adequate for healthcare worker safety at outdoor coronavirus disease 2019 (COVID-19) drive-through testing centers
}

\author{
Johanna B. Warren $\mathrm{MD}^{1}$ (1), Ryan Norton $\mathrm{DO}^{1}$, Dawn Nolt MD, $\mathrm{MPH}^{2}$, Faiza J. Khan MBBS, $\mathrm{MBI}^{3}$ and \\ Judith A. Guzman-Cottrill DO \\ ${ }^{1}$ Department of Family Medicine, Oregon Health and Science University, Portland, Oregon, ${ }^{2}$ Department of Pediatrics, Division of Infectious Diseases, Oregon \\ Health and Science University, Portland, Oregon and ${ }^{3}$ Business Intelligence and Advanced Analytics Information Technology Group, Oregon Health and Science \\ University, Portland, Oregon
}

Author for correspondence: Johanna B. Warren, E-mail: warrejoh@ohsu.edu Cite this article: Warren JB, et al. (2022). Medical facemasks are adequate for healthcare worker safety at outdoor coronavirus disease 2019 (COVID-19) drivethrough testing centers. Infection Control \& Hospital Epidemiology, 43: 411-413, https://doi.org/10.1017/ice.2020.1430
To the Editor-Since the beginning of the coronavirus disease 2019 (COVID-19) pandemic, recommendations for healthcare worker (HCW) respiratory personal protective equipment (PPE) continue to be a topic of debate. The Centers for Disease Control and Prevention (CDC) recommends an N95 respirator or higher level of protection, plus eye protection. ${ }^{1}$ However, the Infectious Disease 